\title{
IV. OBSERVATIONS
}

\author{
$\mathrm{OF}$
}

GLOBAL ACTIVITY

DUE TO INTERACTION 